\title{
HUBUNGAN KESEJAHTERAAN DENGAN KINERJA KARYAWAN PADA POLYTRON SERVICE CENTER LAMPUNG
}

\author{
Yuliayana Yamin ${ }^{(1)^{*}}$, Nuzleha ${ }^{(2)}$, Ridho Rahman Hidayat ${ }^{(3)}$ \\ Fakultas Ekonomi Universitas Sang Bumi Ruwa Jurai \\ *email: yuliayamin0607@gmail.com,nuzlehahadjar1970@gmail.com,ridhorahman21@gmail.com
}

\begin{abstract}
Abstrak. Penelitian ini bertujuan untuk mengetahui hubungan kesejahteraan dengan kinerja karyawan pada polytron service center lampung. Metode yang digunakan dalam penelitian ini menggunakan jenis penelitian deskriptif kuantitatif. Teknik pengumpulan data dilakukan dengan kusioner, observasi dan dokumentasi. Berdasarkan hasil penelitian di dapatkan hasil bahwasnnya kesejahteraan berhubungan dengan kinerja karyawan pada polytron service center lampung. Berdasarkan hasil penelitian menunjukan bahwa kesejahteraan berhubungan dengan kinerja karyawan pada polytron service center Lampung.
\end{abstract}

Kata Kunci: Kesejahteraan, Kinerja, Karyawan

Abstract. This study aims to determine the relationship between welfare and employee performance at the Service Center Polytron Lampung. The method used in this research is descriptive quantitative research. Data collection techniques were carried out by questionnaires, observations and documentation. Results Based on the research, it was found that welfare is related to employee performance at the Politron Lampung Service Center. Based on the results of the study, it shows that welfare is related to employee performance at the Polytron Lampung service center.

Keyword: Welfare, Performance, Employees

\section{PENDAHULUAN}

Untuk mempertahankan karyawan dalam suatu perusahaan, maka perusahaan tersebut haruslah memberikan suatu bentuk balas jasa di luar gaji dan upah. Bentuk balas jasa ini pada umumnya yang dinamakan sebagai program kesejahteraan karyawan. Program kesejahteraan karyawan sangat penting untuk suatu organisasi, karena dengan adanya program kesejahteraan ini maka secara otomatis akan mempertahankan kelangsungan para pegawai dalam bekerja dalam instansi atau organisasi tersebut. Program kesejahteraan yang diberikan organisasi kepada para karyawan dapat berupa tunjangan-tunjangan dan fasilitas serta pelayanan. Tentunya program kesejahteraan ini bermanfaat untuk memenuhi kebutuhan hidup para karyawan beserta keluarganya. Kesejahteraan yang diterapkan di organisasi harus disusun berdasarkan peraturan legal yang berasaskan keadilan dan kelayakan serta berpedoman kepada kemampuan organisasi. Hal ini mampu untuk menciptakan kinerja yang baik, karena dengan adanya pelaksanaan program kesejahteraan karyawan maka dapat memberikan kontribusi yang baik bagi organisasi. produktivitas mereka dalam bekerja. Meningkatnya produktivitas pegawai merupakan harapan setiap organisasi atau perusahaan. Kualitas SDM juga sangat menentukan suatu keberhasilan organisasi, apabila di dalam organisasi tersebut terdapat SDM yang handal maka 
kinerja pegawainya akan tinggi dan tujuan dari organisasi tercapai dengan maksimal. Kinerja pegawai dalam menjalankan fungsinya tidak berdiri sendiri melainkan selalu berhubungan dengan pemberian kompensasi atau insentif sebagai bentuk tingkat kesejahteraan dari pimpinan terhadap bawahan.

Pimpinan dalam organisasi harus dapat mengetahui betapa pentingnya memperhatikan tingkat kesejahteraan karyawan karena dapat meningkatkan semangat kerja, kedisiplinan, serta produktivitas pegawai agar sesuai dengan yang diinginkan oleh pimpinan. Jadi apabila pimpinan kurang memperhatikan kesejahteraan karyawan tersebut maka para karyawan kurang bersemangat melaksanakan tugas. Pemberian kesejahteraan dapat berupa gaji, fasilitas kesehatan atau jamsostek, tunjangan hari raya dan pemberian bonus serta jaminan. Jika pimpinan kurang memperhatikan hal tersebut, maka pegawai akan mengalami kesulitan dan hambatan dalam menjalankan tugas-tugas yang diberikan. Hal ini akan mengakibatkan semangat kerja pegawai akan menurun.

Dalam tahap awal observasi yang penulis lakukan di Polytron Servis Center Lampung, tingkat kesejahteraan yang karyawan dapatkan belum sepenuhnya terpenuhi misalkan karyawan telah melakukan pekerjaan di atas dari target maka bonus yang seharusnya dikeluarkan oleh perusahaan tidak diberikan kepada karyawan, adapun fasilitas seperti mobil perusahaan tidak dengan mudah dipinjamkan kepada karyawan, seminar pelatihan yang berhubungan dengan elektronik tidak rutin diselenggarakan, karyawan cenderung bekerja tidak maksimal, karyawan datang terlambat, dan tidak mempergunakan waktu secara efektif dan efisien, namun penulis harus meneliti lebih jauh terkait hal tersebut.

Berdasarkan penelitian sebelumnya (Wulandari n.d.) Secara bersama-sama (simultan) variabel program kesejahteraan karyawan (program kesejahteraan bersifat ekonomis, fasilitatif dan pelayanan) mempunyai pengaruh terhadap semangat kerja karyawan PT PJB Unit Pembangkitan Gresik.

Sejalan dengan penelitian terssebut(Ramadhany, Habsji, and Mukzam 2013) bahwa Variabel Program Kesejahteraan Karyawan yang bersifat ekonomis mempunyai pengaruh yang signifikan dan berpengaruh positif terhadap variabel semangat kerja dan prestasi kerja, variabel Program Kesejahteraan Karyawan yang bersifat fasilitatif mempunyai pengaruh yang signifikan dan berpengaruh positif terhadap variabel semangat kerja dan prestasi kerja, dan variabel semangat kerja mempunyai pengaruh yang signifikan dan berpengaruh positif terhadap prestasi kerja. Program kesejahteraan yang bersifat ekonomis dan fasilitatif, semangat kerja, dan prestasi kerja baik secara parsial maupun simultan berpengaruh dan memiliki koefisien determinasi.

Penulis tertarik untuk meneliti tingkat kesejahteraan yang diterapkan di Polytron Servis Center Lampung apakah sudah diterapkan dan berjalan secara adil dan layak serta sesuai dengan peraturan legal organisasi tersebut. Dengan adanya kesejahteraan yang diberikan oleh Polytron Servis Center Lampung diharapkan mampu mendorong tingkat kinerja karyawan dalam melakukan pekerjaan serta tanggung 
jawab mereka di kantor. Setelah penulis memaparkan sedikit ulasan latar belakang di atas, maka penulis tertarik melakukan penelitian dengan judul "Hubungan Kesejahteraan dengan Kinerja Karyawan Pada Polytron Servis Center Lampung"

\section{METODE PENELITIAN}

Penelitian ini dilakukan di Polytron Servis Center Lampung, yang beralamatkan di Jl. Hos Cokroaminoto No. 75 Rawa Laut, Bandar Lampung. Penelitian ini dilakukan selama bulan Maret - Mei 2020 di Polytron Servis Center Lampung. Dengan obyek utama dalam penelitian ini adalah karyawan Polytron Servis Center Lampung.

Metode Pengumpulan Data

Dalam penelitian ini jenis data yang diperlukan adalah :

\section{a) Data Primer}

Data primer dalam hal ini merupakan data yang diperoleh langsung tanpa perantara orang atau lembaga lain sebagai pihak ketiga. Data primer ini diperoleh dengan wawancara melalui responden dengan menggunakan daftar pertanyaan.

b) Data Sekunder

Merupakan data yang diperoleh melalui orang lain yang berhubungan dengan permasalahan yang dipecahkan. Data sekunder ini diperoleh melalui cara studi dokumenter yaitu mengumpulkan dan mempelajari brosur-brosur serta dokumen organisasi.

Teknik Pengumpulan Data

Untuk mendapatkan dan mengumpulkan data yang sesuai dengan kebutuhan dalam penelitian ini maka teknik-teknik yang digunakan adalah sebagai berikut :

1. Observasi
Yaitu melakukan penelitian dengan pengamatan langsung dengan cara mendekati objek yang akan diteliti. Observasi ini penulis lakukan untuk mengetahui tentang permasalahan kesejahteraan dan kinerja.

2. Wawancara

Adalah proses tanya jawab dalam penelitian yang berlangsung secara lisan dalam mana dua orang atau lebih bertatap muka mendengarkan secara langsung informasiinformasi atau keterangan-keterangan yang berhubungan dengan kesejahteraan dan kinerja.

\section{Kuisioner (Angket)}

Yaitu pengumpulan data dengan cara menyebarkan daftar pertanyaan kepada Polytron Servis Center Lampung. Kuesioner adalah pengumpulan data yang dilakukan dengan cara memberi seperangkat pernyataan tertulis kepada responden untuk disikapinya (Sugiono,

2011:142)

\section{Dokumentasi}

Dokumen merupakan sumber data yang digunakan untuk melengkapi penelitian, baik berupa sumber tertulis, film, gambar (foto), dan karya- karya monumental, yang semuanya itu memberikan informasi.

Untuk menentukan populasi dan sampel dalam penelitian ini menggunakan teori yang diungkapkan oleh Arikunto (2012:14) menyatakan ukuran minimum sampel untuk keperluan penelitian ini lebih dari 100 orang diambil sebanyak $10 \%$ dari jumlah keseluruhan populasi. Untuk keperluan penelitian ini maka sampel diambil dari jumlah populasi 
karyawan Polytron Servis Center Lampung (Arikunto, 2012:21). Populasi yang akan diteliti oleh penulis adalah responden yang berupa karyawan Polytron Servis Center Lampung secara kolektif dengan pengisian angket atau observasi, yaitu dengan mengambil sampel berdasarkan kegiatan dari cluster atau dalam kondisi normal dan mau memberikan jawaban pada angket yang diberikan. Dalam peneilitian ini teknik sampel jenuh digunakan sebab jumlah populasi tidak memenuhi standar statistika dengan jumlah sampel 30 responden.

\section{Alat Analisis}

Sebelum alat pengumpul data digunakan, terlebih dahulu dilakukan ujicoba terhadap alat ukur dengan tujuan untuk mengetahui reliabilitas ini angket yang akan digunakan, sehingga hasil pengukuran yang akan diperoleh nantinya dapat dipertanggung jawabkan. Untuk itu uji reliabilitas digunakan sebagai alat ukur dengan teknik Alpha Cronbach melalui program statistika pada. Pedoman yang digunakan untuk rentang besarnya koefisien

pada teknik Alpha Chronbach adalah sebagai berikut: George (2013).

\section{Analisis Kuantitatif}

Yaitu suatu analisis dengan menggunakan data yang ada, kemudian menguraikan hasil penelitian dalam bentuk angka-angka melalui uji statistik yang tepat dan relevan. Hal ini dimaksudkan agar memudahkan dalam pengolahannya dan teruji kebenarannya, karena data berupa angka maka akan lebih mudah pula dalam penarikan kesimpulan. Untuk menganalisis data dengan ada atau tidaknya hubungan antara Kesejahteraan (variabel $\mathrm{x}$ ) dengan Kinerja (variabel Y).
Menggunakan analisis statistik korelasi product moment:

\section{HASIL DAN PEMBAHASAN}

\section{Analisis Kuantitatif}

Data primer digunakan dalam analisis penelitian ini dalam bentuk data cross section yang diperoleh dari kuesioner dan sudah diolah oleh peneliti terdahulu. Sebelum melakukan penelitian dengan dasar metode penelitian maka angket penelitian diujikan terlebih dahulu untuk diketahui tingkat keakuratan instrumen penelitian. Dari hasil uji coba angket pada responden setara terhadap variabel-variabel yang akan diteliti kepada 30 responden setara atau responden percobaan yang berhasil didapatkan penulis, diperoleh hasil sebagai berikut:

a. Hasil Uji Validitas Butir Variabel Bebas Tabel 1

Uji Validitas Butir Variabel X

\begin{tabular}{|c|c|c|c|c|c|c|c|c|}
\hline \multicolumn{9}{|c|}{ Correlations } \\
\hline & & $x 1$ & $x 2$ & $x 3$ & $x 4$ & $\times 5$ & $\times 6$ & $x$ \\
\hline \multirow[t]{3}{*}{$x 1$} & Pearson Correlation & 1 & $605^{\prime \prime}$ & ,505" & $605^{\prime \prime}$ & ,505" & $618^{\prime \prime}$ &, $748^{\prime \prime}$ \\
\hline & Sig. (2-tailed) & & , 001 & ,010 & , 001 & ,010 & 001 & ,000 \\
\hline & $\mathrm{N}$ & 25 & 25 & 25 & 25 & 25 & 25 & 25 \\
\hline$x 2$ & Pearson Correlation & $.605^{*}$ & 1 & $.495^{\circ}$ & $1,000^{*}$ & $495^{\circ}$ & $.525^{*}$ & $801^{\prime \prime}$ \\
\hline & Sig. (2-tailed) & ,001 & & ,012 &, 000 & ,012 & ,007 & ,000 \\
\hline & $\mathrm{N}$ & 25 & 25 & 25 & 25 & 25 & 25 & 25 \\
\hline \multirow[t]{3}{*}{$\times 3$} & Pearson Correlation &, $505^{\prime \prime}$ & $495^{*}$ & 1 & $.495^{\circ}$ & $1,000^{\prime \prime}$ & $873^{\prime \prime}$ & $890^{\prime \prime}$ \\
\hline & Sig. (2-tailed) & ,010 & ,012 & &, 012 &, 000 &, 000 & ,000 \\
\hline & $\mathrm{N}$ & 25 & 25 & 25 & 25 & 25 & 25 & 25 \\
\hline \multirow[t]{3}{*}{$x 4$} & Pearson Correlation & $605 "$ & $1,000^{\prime \prime}$ & $495^{\circ}$ & 1 & $495^{\circ}$ & $.525^{\prime \prime}$ & $801^{\prime \prime}$ \\
\hline & Sig. (2-tailed) &, 001 &, 000 & .012 & & .012 & .007 &, 000 \\
\hline & $\mathrm{N}$ & 25 & 25 & 25 & 25 & 25 & 25 & 25 \\
\hline \multirow[t]{3}{*}{$\times 5$} & Pearson Correlation &, $505^{\prime \prime}$ & $495^{\circ}$ & $1,000^{\prime \prime}$ & $495^{\circ}$ & 1 & $873^{*}$ & $890^{\circ}$ \\
\hline & Sig. (2-tailed) & ,010 & ,012 & ,000 & ,012 & & ,000 & ,000 \\
\hline & N & 25 & 25 & 25 & 25 & 25 & 25 & 25 \\
\hline \multirow[t]{3}{*}{$x 6$} & Pearson Correlation & $.618^{\prime \prime}$ & $.525^{\prime \prime}$ & ,873" &, $525^{*}$ & $873^{\prime \prime}$ & 1 & $888^{\prime \prime}$ \\
\hline & Sig. (2-tailed) & ,001 & ,007 &, 000 & , 007 & ,000 & & ,000 \\
\hline & $\mathrm{N}$ & 25 & 25 & 25 & 25 & 25 & 25 & 25 \\
\hline \multirow[t]{3}{*}{$x$} & Pearson Correlation & ,748" & $801^{\prime \prime}$ & ,890" & $801^{\prime \prime}$ & $890^{\prime \prime}$ & $8888^{\prime \prime}$ & 1 \\
\hline & Sig. (2-tailed) & ,000 & ,000 & ,000 &, 000 & ,000 & ,000 & \\
\hline & $\mathrm{N}$ & 25 & 25 & 25 & 25 & 25 & 25 & 25 \\
\hline
\end{tabular}


Reliability Statistics

\begin{tabular}{|r|r|}
\hline $\begin{array}{c}\text { Cronbach's } \\
\text { Alpha }\end{array}$ & N of Items \\
\hline, 914 & 6 \\
\hline
\end{tabular}

Sumber: Data Primer Hasil Uji coba (SPSS)

b. Hasil Uji Validitas Butir Pertanyaan Variabel Y

Tabel 2

Uji Validitas Butir Pertanyaan Variabel Y

\begin{tabular}{|c|c|c|c|c|c|c|c|c|}
\hline \multicolumn{9}{|c|}{ Correlations } \\
\hline & & $y 1$ & 12 & $\beta$ & $y^{4}$ & y5 & y6 & $y$ \\
\hline \multirow[t]{3}{*}{$\overline{y^{11}}$} & Pearson Correlation & 1 & 370 &, 328 & $.456^{\circ}$ & $1,000^{\prime \prime}$ & .328 & $655^{\prime \prime}$ \\
\hline & Sig. (2-tailed) & & ,069 & ,110 &, 022 &, 000 & .110 &, 000 \\
\hline & $\mathrm{N}$ & 25 & 25 & 25 & 25 & 25 & 25 & 25 \\
\hline \multirow[t]{3}{*}{$y^{2}$} & Pearson Correlation & 370 & 1 &, $578^{*}$ &, $646^{*}$ &, 370 &, $578^{\prime \prime}$ & 814 \\
\hline & Sig. (2-tailed) &, 069 & &, 002 &, 000 & 069 & .002 &, 000 \\
\hline & N & 25 & 25 & 25 & 25 & 25 & 25 & 25 \\
\hline \multirow[t]{3}{*}{$y_{3}$} & Pearson Correlation & 328 & ,578" & 1 &, $798^{\prime \prime}$ &, 328 & $1,000^{\prime \prime}$ & $854 "$ \\
\hline & Sig. (2-tailed) & , 110 & ,002 & &, 000 & 110 & .000 &, 000 \\
\hline & $\mathrm{N}$ & 25 & 25 & 25 & 25 & 25 & 25 & 25 \\
\hline \multirow[t]{3}{*}{$y 4$} & Pearson Correlation & $.456^{\circ}$ &, $646^{*}$ &, $798^{*}$ & 1 & $.456^{*}$ & $.798^{\prime \prime}$ & $892^{\prime \prime}$ \\
\hline & Sig. (2-tailed) &, 022 & , 000 &, 000 & & ,022 & .000 &, 000 \\
\hline & $\mathrm{N}$ & 25 & 25 & 25 & 25 & 25 & 25 & 25 \\
\hline \multirow[t]{3}{*}{$y^{5}$} & Pearson Correlation & $1,000^{\prime \prime}$ & ,370 & ,328 & $.456^{\circ}$ & 1 &, 328 & $655^{\prime \prime}$ \\
\hline & Sig. (2-tailed) &, 000 & 069 & ,110 & 0,022 & &, 110 &, 000 \\
\hline & $\mathrm{N}$ & 25 & 25 & 25 & 25 & 25 & 25 & 25 \\
\hline \multirow[t]{3}{*}{ yo } & Pearson Correlation & 328 &, $578^{\prime \prime}$ & $1,000^{*}$ &, $798^{\prime \prime}$ &, 328 & 1 & $854^{\prime \prime}$ \\
\hline & Sig. (2-tailed) & ,110 & ,002 &, 000 &, 000 & 110 & &, 000 \\
\hline & $\mathrm{N}$ & 25 & 25 & 25 & 25 & 25 & 25 & 25 \\
\hline \multirow[t]{3}{*}{ y } & Pearson Correlation & $655^{\prime \prime}$ & $814^{\prime \prime}$ & $854^{\prime \prime}$ & $892^{\prime \prime}$ & $655^{\prime \prime}$ & $854^{\prime \prime}$ & 1 \\
\hline & Sig. (2-tailed) &, 000 & , 000 &, 000 &, 000 &, 000 &, 000 & \\
\hline & $\mathrm{N}$ & 25 & 25 & 25 & 25 & 25 & 25 & 25 \\
\hline
\end{tabular}

\section{Reliability Statistics}

\begin{tabular}{|r|r|}
\hline $\begin{array}{c}\text { Cronbach's } \\
\text { Alpha }\end{array}$ & N of Items \\
\hline, 879 & 6 \\
\hline
\end{tabular}

Sumber: Data Primer Hasil Uji coba (SPSS)

Dari hasil pengujian tabel di atas, menunjukan validitas (corrected item-total correlation) koefisien korelasi item pada variabel $\mathrm{X}$ dan $\mathrm{Y}$ seluruhnya valid. Hasil analisis uji reliabilitas yang terjadi menunjukkan bahwa kuesioner reliable, karena skor alpha positif dengan nilai 0.914 untuk alpha $\mathrm{X}$ dan 0.879 untuk alpha $\mathrm{Y}$ dan lebih besar dari 0.6 (Arikunto, 2012). Dengan demikian dapat dikatakan kuesioner variabel $\mathrm{X}$ dan $\mathrm{Y}$ layak untuk digunakan dalam pengambilan data penelitian.

Analisis Data

Guna memudahkan dan pencapaian target analisis yang akurat, maka dalam operasional analisis data digunakan program statistika pengolahan data dalam penelitian ini responden berjumlah 50 responden, yang dapat digunakan dalam keadaan baik. Sebelum dilakukan pengolahan data dilakukan uji terhadap asumsi klasik untuk menghindari asumsi klasik yaitu uji normalitas, dan uji homogenitas.

\section{Uji Normalitas}

Dengan menggunakan program SPSS, hasil uji normalitas yang dilakukan dapat dilihat dengan hasil grafik normalitas, yang ditampilkan sebagai berikut:

\section{Gambar 1}

\section{Grafik Normalitas}

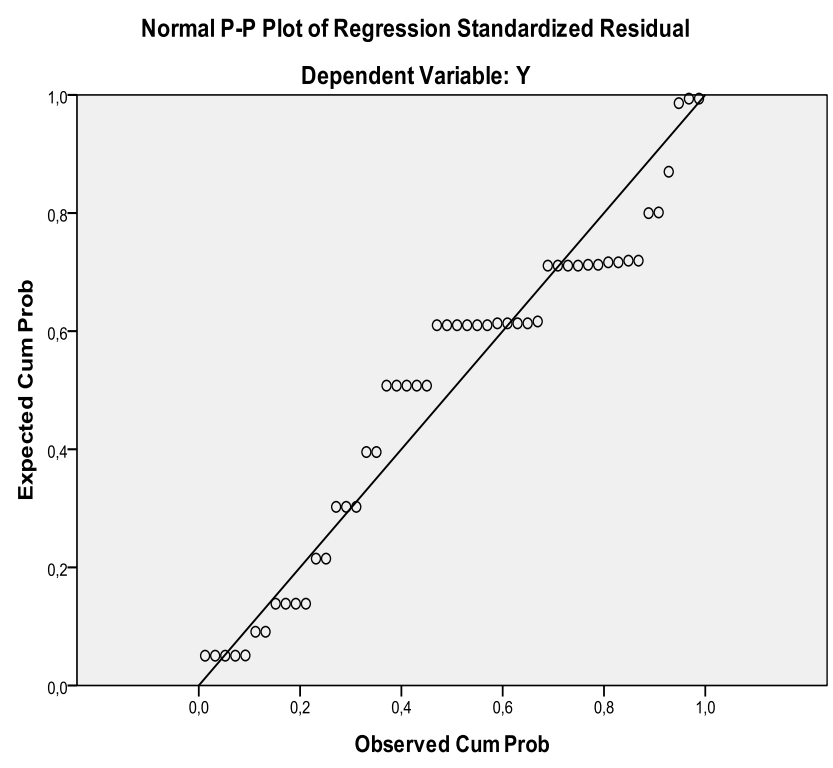

Sumber data : Grafik SPSS 
Pola penyebaran yang terjadi berada pada sekitar garis diagonal dan mengikuti garis diagonal tersebut berisifat moderate tetapi masih disekitaran sumbu normal. Ini berarti bahwa model regresi dalam penelitian ini sudah memenuhi asumsi normalitas dengan nilai moderate, yaitu variabel - variabel yang digunakan dalam penelitian ini mempunyai distribusi yang normal.

Uji Homogenitas

Untuk menguji homogenitas digunakan metode visual berdasarkan hasil olahan data dengan program SPSS yaitu dengan cara melihat penyebaran nilai-nilai residual terhadap nilai prediksi.sebagai berikut :

\section{Gambar 2}

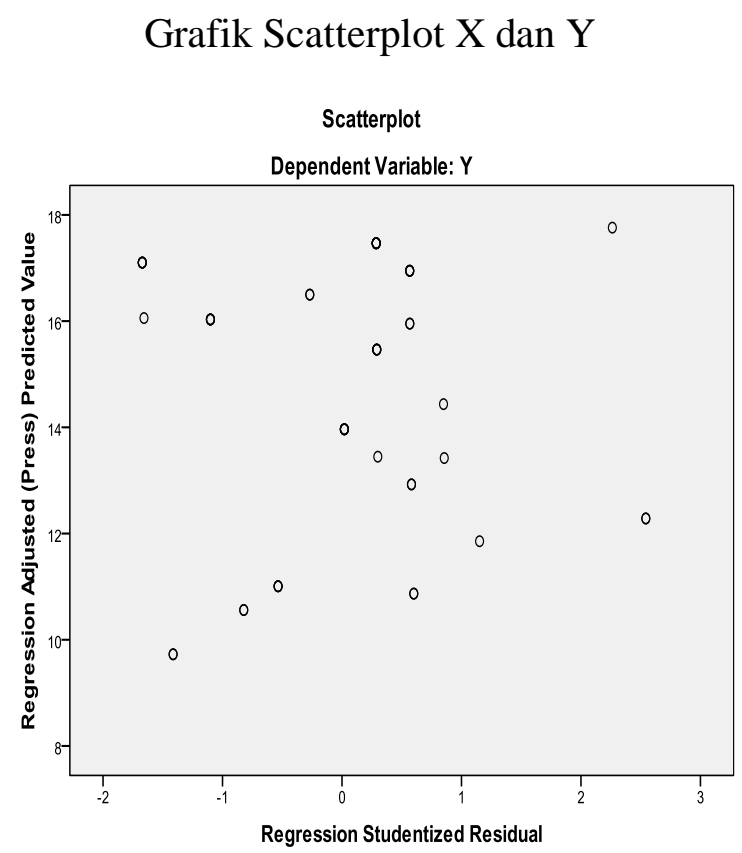

Sumber : Hasil Olah Data SPSS

Berdasarkan seluruh gambar grafik di atas, diketahui bahwa penyebaran nilai - nilai perbandingan tersebut tidak membentuk pola tertentu sehingga keadaan homogenitas dapat terpenuhi pada homogenitas Variabel X1 dan Variabel Y. Maka berdasarkan hasil uji data Normalitas dan Homogentitas data penelitian dapat dilanjutkan ke uji selanjutnya yaitu regresi.

Hasil Penelitian

Setelah uji Normalitas dan Homogenitas terpenuhi maka data siap untuk dilakukan dengan pembuktian hipotesis penelitian. Hasil uji regresi linear yang dilakukan dengan menggunakan program statistika (SPSS) dengan acuan hasil perhitungan analisis statistik data dijelaskan sebagai berikut:

Model persamaan regresi untuk fungsi ini adalah :

$$
\mathbf{Y}=\mathbf{a}+\mathbf{b X}
$$

\section{Dimana}

Y

$\mathrm{X} \quad=\quad$ kepuasan kerja

a $\quad=\quad$ konstanta

$\mathrm{b} \quad=\quad$ koefisien regresi

Acuan hasil tersebut dapat digunakan sebagai panduan dalam mengartikan hasil dari pengolahan data dengan menggunakan program SPSS. Hasil diperoleh model regresi linier dengan Pembuktian Hipotesis "diduga ada Pengaruh Kepuasan Terhadap Kinerja Pegawai di Bidang Program dan Perencanaan Umum Balai Besar Wilayah Sungai Mesuji Sekampung di Bandar Lampung". Berdasarkan hasil analisis data maka hasil analisis yang didapatkan adalah sebagai berikut:

Tabel 3

Hasil Analisis Hipotesis 
Coefficientis $^{a}$

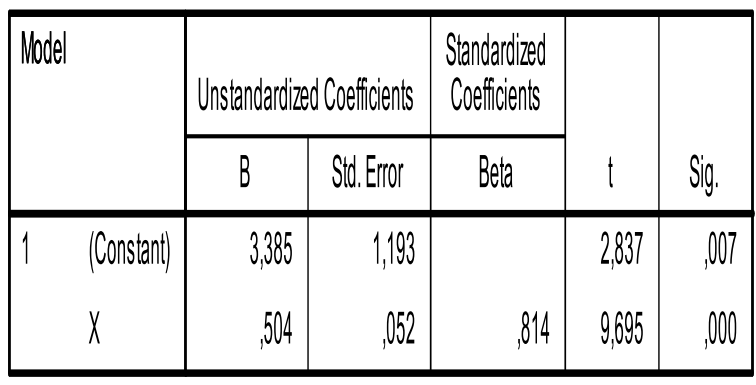

a. Dependent Variable: Y

Sumber: Hasil Oleh Data SPSS

Model Summary ${ }^{b}$

\begin{tabular}{|l|c|c|c|c|}
\hline Model & $\mathrm{R}$ & $\mathrm{R}$ Square & $\begin{array}{c}\text { Adjusted } \mathrm{R} \\
\text { Square }\end{array}$ & $\begin{array}{c}\text { Std. Error of } \\
\text { the Estimate }\end{array}$ \\
\hline 1 &, $814^{\mathrm{a}}$ &, 662 &, 655 & 1,82110 \\
\hline
\end{tabular}
a. Predictors: (Constant), $\mathrm{X}$
b. Dependent Variable: $Y$

Berdasarkan hasil uji tersebut maka didapatkan persamaan model regresi yang sebagai berikut :

$$
\begin{array}{lc}
\mathrm{Y} & =3,385 \quad+0,504 \mathrm{X} \\
\mathrm{t} \text { hitung } & \multicolumn{1}{c}{=(2,837)} \\
(9,695) & \\
\mathrm{R} 2 & =0.662 \\
\mathrm{~N} & =50
\end{array}
$$

Dari hasil regresi yang telah didapat, maka dapat hasil penelitian dapat diinterpretasikan pada Uji $t$ yang dilakukan untuk melihat besarnya pengaruh secara individu variabel bebas terhadap variabel tak bebas. Dan hasil estimasi dapat kita lihat bahwa nilai t hitung untuk variabel (X) sebesar 9,695 (Prob.sig. $=0,000)$ yang berarti $\mathrm{t}$ hitung $>\mathrm{t}$ tabel dengan tingkat signifikansi 95\% (persen). Kemudian koefisien determinasi (R2) memiliki nilai yang sedang yaitu sebesar 0,662 yang berarti $66,2 \%$ memiliki pengaruh sedang pada kepuasan kerja terhadap kinerja. Setelah dilakukan pembuktian hipotesis, selanjutnya dilakukan analisis untuk menguji kaitan butir terhadap variabel dan dilakukan pada setiap variabel uji guna mendapatkan hasil kontribusi butir yang lebih detail pada setiap variabel dengan menggunakan perthitungan rata - rata jawaban, Arikunto (2012). Berikut ditampilkan hasil uji rata - rata butir terhadap variabel uji yang ditampilkan dalam tabel sebagai berikut:

Tabel 4.

Hasil Analisis Rata Rata Jawaban Butir Pada Konsep

\begin{tabular}{|c|c|c|c|c|c|c|}
\hline Variabel & \multicolumn{6}{|c|}{ No Quesioner pada Angket } \\
\hline Item & 1 & 2 & 3 & 4 & 5 & 6 \\
\hline Kepuasan Kerja & 3.05 & 3.63 & 4.13 & 3.63 & 4.13 & 4.4 \\
\hline Variabel & \multicolumn{7}{|c|}{ No Quesioner pada Angket } \\
\hline Item & 1 & 2 & 3 & 4 & 5 & 6 \\
\hline Kinerja & 3,07 & 3.70 & 3.83 & 4.23 & 3.05 & 3.7 \\
\hline
\end{tabular}

\section{Sumber: Hasil Oleh Data SPSS}

Berdasarkan hasil uji tersebut diketahui bahwa butir dengan rata - rata yang paling kecil pada variabel Kepuasan kerja adalah butir X1. Kemudian pada Variabel kinerja adalah butir Y5. Guna memudahkan interpretasi dari hasil regresi linier sederhana yang digabungkan dengan kontribusi pada butir terhadap variabel ujinya pada variabel - variabel yang mempengaruhi maka hasil analisis dirangkum dan dapat diinterpretasikan bahwa kepuasan kerja memiliki pengaruh yang sedang yaitu sebesar $66,2 \%$ terhadap kinerja pada Pegawai Kegiatan Ketatalaksanaan di Kantor Balai Besar Wilayah Sungai Mesuji Sekampung di Bandar Lampung. Pada variabel Kepuasan kerja juga didapatkan yaitu bahwa butir Anda dapat bekerja dengan team kerja 
dengan baik, memiliki kontribusi yang paling kecil. Kemudian pada variabel Kinerja butir yang paling kecil adalah Tidak menunda pekerjaan yang telah diberikan pimpinan.

\section{KESIMPULAN}

Berdasarkan hasil penelitian Kesejahteraan memiliki hubungan yang sedang yaitu sebesar $52.1 \%$ terhadap Kinerja pada Karyawan Pada Polytron Servis Center Lampung. Pada variabel Insentif juga didapatkan bahwa butir Organisasi anda memberi anda kesempatan untuk maju, memiliki kontribusi yang paling kecil. Kemudian Pada variabel Kinerja butir yang paling kecil adalah Anda selalu berusaha setia dengan apa yang diputuskan oleh organsiasi anda. Dari pengolahan data juga didapatkan bahwa masih ada variabel lain tetapi tidak begitu besar pengaruhnya yang belum dimasukkan tetapi memiliki pengaruh pada Kinerja sebesar $47.9 \%$

\section{Saran}

Atas dasar hasil penelitian tersebut diatas, maka akan dikemukakan beberapa saran sebagai berikut :

\section{Polytron Servis Center Lampung}

Pada variabel Kesejahteraan disarankan agar perusahaan lebih memperhatikan asuransi yang pasti diberikan kepada karyawan. Sedangkan pada variabel Kinerja diharapkan perusahaan dapat memberi list pekerjaan kepada karyawan agar dapat menyelesaikan pekerjaan sesuai waktu dan target yang ditentukan kantor.

\section{Bagi Keilmuan}

Diharapkan adanya penelitian lanjutan untuk memastikan pengaruh pada model yang terjadi. Hal ini terjadi disebabakan adanya faktor di luar model sebesar $47.9 \%$. Oleh sebab itu dibutuhkan penelitian lain guna mengembangkan model disebabkan sifat penelitian ini dapat mengalami perubahan seperti pada konsep Disiplin, Kompensasi, Pendidikan, Golongan dan Promosi Jabatan yang tidak diteliti dalam penelitian ini

\section{UCAPAN TERIMAKASIH}

Terimakasih kepada Universitas Sang Bumi Ruwa Jurai yang telah berkontribusi dalam penelitian ini. 


\section{DAFTAR PUSTAKA}

Arikunto, Suharsimi, 2012. Prosedur

Penelitian-Suatu Pendekatan

Praktek, Jakarta:Penerbit Bina Aksara

Flippo, Edwin B. 2015. Manajemen Sumber

Daya Manusia, Jakarta: Penerbit

Bina Aksara

Handoko, T. Hani. 2015. Manajemen Sumber Daya Manusia, Yogyakarta: Penerbit BPFE

Hasibuan, Malayu S.P., 2012. Manajemen Sumber Daya Manusia, Jakarta: Penerbit Bumi Aksara

Hujaimatul Fauziah, Maruli Susanto Efendi 2018. Analysis Incentive of Employee Work Spirit PT. Indomarco Prismatama Lampung Branch. IJSSD: International Journal Of Social Sciences and Development.

Jashinta, Renny.2014. Pengaruh Kesejahteraan Karyawan Terhadap Kinerja Karyawan Pada PT. Pegadaian (Persero) Kantor Wilayah III Palembang. Politeknik Negeri Sriwijaya Palembang.

M. Irfan, Noviar Arif. 2020. Analisis Pengaruh Tingkat Kesejahteraan, Upah Lembur, dan Motivasi Kerja Terhadap Kinerja Karyawan Hotel Grand Dian Slawi. Fakultas
Ekonomi, Universitas Pancasakti Tegal

Manullang, M. 2012. Manajemen Personalia, Jakarta: Penerbit PT Ghalia Indonesia

Martoyo, Susilo, 2010. Pengantar Manajemen Sumber Daya Manusia, Bandung: Penerbit Tarsito.

Nitisesmito, Alex S. 2015, Manajemen Personalia, Jakarta: Penerbit PT Ghalia Indonesia

Nuzleha, Putri Yumarni. 2018. Hubungan Kesejahteraan Pegawai Dengan

Rahman, Fazlul . 2014. Analisis Tingkat Kesejahteraan Keluarga Karyawan di PT. Mopoli Raya Kabupaten Aceh Tamiang. ETD, Fakultas Agribisnis Universitas Syiah Kuala.

Ranupandojo, Heidjrachman dan Suad, Husnan, 2010. Perilaku Organisasi, Bandung: Penerbit Angkasa

Rivai,Veithzal, 2011, Manajemen Sumber Daya Manusia untuk Perusahaan, Jakarta: Rajagrafindo Persada

Siagian, Sondang P. 2011. Manajemen Sumber Daya Manusia, Jakarta: Penerbit Gramedia 
Sinungan, Muchdarsyah, 2017, Manajemen Personalia, Jakarta: Penerbit Ghalia Indonesia

Syadam, Gauzali.2016. Manajemen

Personalia Suatu Pendekatan
Makro, Jakarta: Penerbit Djambatan. 